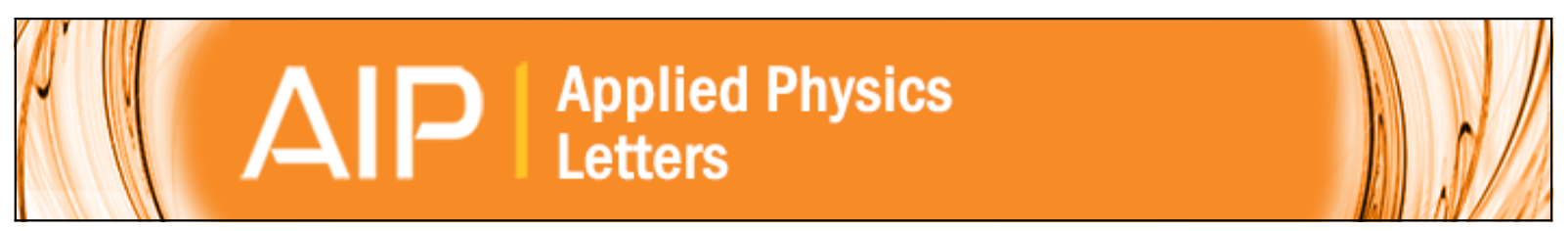

\title{
Colloidal quantum dot solar cells on curved and flexible substrates
}

Illan J. Kramer, Gabriel Moreno-Bautista, James C. Minor, Damir Kopilovic, and Edward H. Sargent

Citation: Applied Physics Letters 105, 163902 (2014); doi: 10.1063/1.4898635

View online: http://dx.doi.org/10.1063/1.4898635

View Table of Contents: http://scitation.aip.org/content/aip/journal/apl/105/16?ver=pdfcov

Published by the AIP Publishing

\section{Articles you may be interested in}

Efficient, air-stable colloidal quantum dot solar cells encapsulated using atomic layer deposition of a nanolaminate barrier

Appl. Phys. Lett. 103, 263905 (2013); 10.1063/1.4858135

Hybrid polymer solar cell based on cadmium selenide quantum dots

AIP Conf. Proc. 1536, 213 (2013); 10.1063/1.4810176

Impact of $\mathrm{CdSe} / \mathrm{ZnS}$ quantum dot spectrum converters on InGaP/GaAs/Ge multi-junction solar cells

J. Vac. Sci. Technol. A 30, 011201 (2012); 10.1116/1.3673784

Colloidal quantum dot absorption enhancement in flexible Fano filters

Appl. Phys. Lett. 96, 083111 (2010); 10.1063/1.3337095

Characterization of electrospray ion-beam-deposited CdSe/ZnS quantum dot thin films from a colloidal solution J. Vac. Sci. Technol. A 26, 1058 (2008); 10.1116/1.2912072

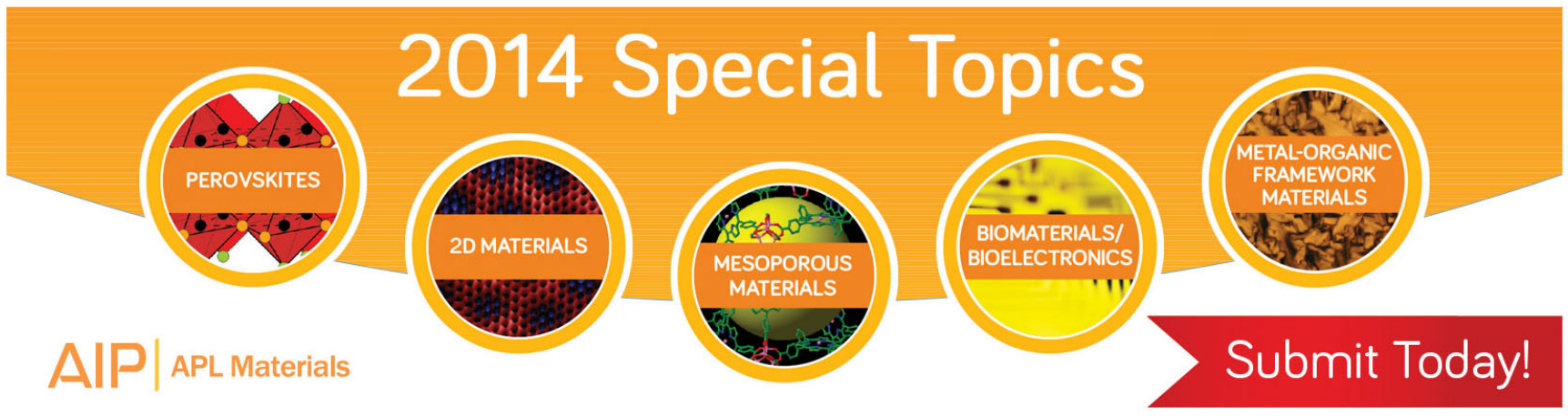




\title{
Colloidal quantum dot solar cells on curved and flexible substrates
}

\author{
Illan J. Kramer, ${ }^{1,2, a)}$ Gabriel Moreno-Bautista, ${ }^{1, a)}$ James C. Minor, ${ }^{1}$ Damir Kopilovic, ${ }^{1}$ \\ and Edward H. Sargent ${ }^{1, b)}$ \\ ${ }^{1}$ Department of Electrical and Computer Engineering, University of Toronto, 10 King's College Road, \\ Toronto, Ontario M5S 3G4, Canada \\ ${ }^{2}$ IBM Canada Research \& Development Centre, 120 Bloor Street East, Toronto, Ontario, M4W 1B7, Canada
}

(Received 19 August 2014; accepted 6 October 2014; published online 21 October 2014)

Colloidal quantum dots (CQDs) are semiconductor nanocrystals synthesized with, processed in, and deposited from the solution phase, potentially enabling low-cost, facile manufacture of solar cells. Unfortunately, CQD solar cell reports, until now, have only explored batch-processing methods - such as spin-coating - that offer limited capacity for scaling. Spray-coating could offer a means of producing uniform colloidal quantum dot films that yield high-quality devices. Here, we explore the versatility of the spray-coating method by producing CQD solar cells in a variety of previously unexplored substrate arrangements. The potential transferability of the spray-coating method to a roll-to-roll manufacturing process was tested by spray-coating the CQD active layer onto six substrates mounted on a rapidly rotating drum, yielding devices with an average power conversion efficiency of $6.7 \%$. We further tested the manufacturability of the process by endeavoring to spray onto flexible substrates, only to find that spraying while the substrate was flexed was crucial to achieving champion performance of $7.2 \%$ without compromise to open-circuit voltage. Having deposited onto a substrate with one axis of curvature, we then built our CQD solar cells onto a spherical lens substrate having two axes of curvature resulting in a 5\% efficient device. These results show that CQDs deposited using our spraying method can be integrated to large-area manufacturing processes and can be used to make solar cells on unconventional shapes. (C) 2014 AIP Publishing LLC. [http://dx.doi.org/10.1063/1.4898635]

Colloidal quantum dots (CQDs) enable photovoltaic technologies that feature size-effect tunability of their bandgap as well as deposition from the solution phase. ${ }^{1,2}$ Solution processing offers the potential for CQD solar cells to be fabricated using large area, roll-to-roll (R2R) manufacturing techniques. However, to date, CQD solar cell device reports have been limited to batch fabrication methods such as spin coating ${ }^{3,4}$ and dip coating. ${ }^{5,6}$

Spray coating is a fabrication method compatible with $\mathrm{R} 2 \mathrm{R}$ processing, and has been previously used to deposit photovoltaic films in other material systems. ${ }^{7,8}$ We have recently developed a spray-coating process for CQDs that produces high-quality photovoltaic films that exhibit power conversion efficiencies that are comparable to that of their spin-cast counterparts. These films are composed of ultrathin layers of CQDs approaching a single monolayer. The deposit-develop-repeat nature of the monolayer-by-monolayer procedure represents an analogue to the atomic layer deposition (ALD) process ${ }^{9}$ for producing high quality oxides ${ }^{10}$ and sulphides. ${ }^{11}$ For this reason, we have termed the process "sprayLD." Initial findings suggest the promise of manufacturability without compromise to device performance. ${ }^{12}$

Here, we sought to investigate the versatility of the sprayLD method by fabricating solar cells on a variety of substrates of practical interest in scale-up manufacture and field deployment. In this study, we built solar cells using the widely adopted depleted heterojunction architecture, ${ }^{13}$

\footnotetext{
a) I. J. Kramer and G. Moreno-Bautista contributed equally to this work.

${ }^{b)}$ Author to whom correspondence should be addressed. Electronic mail: ted.sargent@utoronto.ca.
}

wherein titanium dioxide $\left(\mathrm{TiO}_{2}\right)$ coats a transparent conductive oxide such as fluorine-doped tin oxide (FTO) or indium doped tin oxide (ITO), and this is in turn is overcoated by the CQD layer. The cell is completed with metallic contacts ohmic to the CQD layer.

The PbS quantum dots that were used in this study were synthesized according to a previously published method. ${ }^{14} \mathrm{~A}$ solution-phase metal halide treatment $\left(\mathrm{CdCl}_{2}\right)$ was then carried out following a previously published method. ${ }^{15}$ The stock $50 \mathrm{mg} / \mathrm{mL}$ CQD in octane solution was diluted to $3.33 \mathrm{mg} / \mathrm{mL}$ immediately prior to use. The total solution volume required for one device was $18.75 \mathrm{~mL}$, yielding a mass of oleic acidcapped CQDs of approximately $62.5 \mathrm{mg}$. Our sprayLD process is summarized in Figure 1(a). The CQD solution was placed in a reservoir connected to the solution gravity-fed inlet of an Ikeuchi fine mist nozzle (BIMV8002S). The nozzle was pressurized to $45 \mathrm{psi}$ using a $\mathrm{N}_{2}$ gas line. Another $45 \mathrm{psi}$ $\mathrm{N}_{2}$ gas line provides activated piston control for the nozzle. Mercaptopropionic acid (MPA) was diluted in methanol $(\mathrm{MeOH})$ to $0.16 \%$ (v:v) and placed in a reservoir for a Paasche VL airbrush pressurized with a $35 \mathrm{psi}_{2}$ gas line. A third $45 \mathrm{psi}_{2}$ gas line pressurized an additional Paasche VL airbrush or Ikeuchi flat-spray hydraulic nozzle (1/8(PT)VVP) loaded with $\mathrm{MeOH}$. Finally, a custom made air blade was connected to an $85 \mathrm{psi}$ compressed dry air gas line. Fabrication consisted of between 65 and 85 layers of a sprayed layer-by-layer procedure where each layer included: $0.4 \mathrm{~s}$ actuated CQD nozzle followed by a $3 \mathrm{~s}$ pause, $1 \mathrm{~s}$ actuated MPA nozzle, $4 \mathrm{~s} \mathrm{MeOH}$ rinse for airbrush or $0.5 \mathrm{~s} \mathrm{MeOH}$ rinse for hydraulic nozzle, and $40 \mathrm{~s}$ air blade drying. In all experiments, the CQD, MPA, and $\mathrm{MeOH}$ nozzles as well as 
a

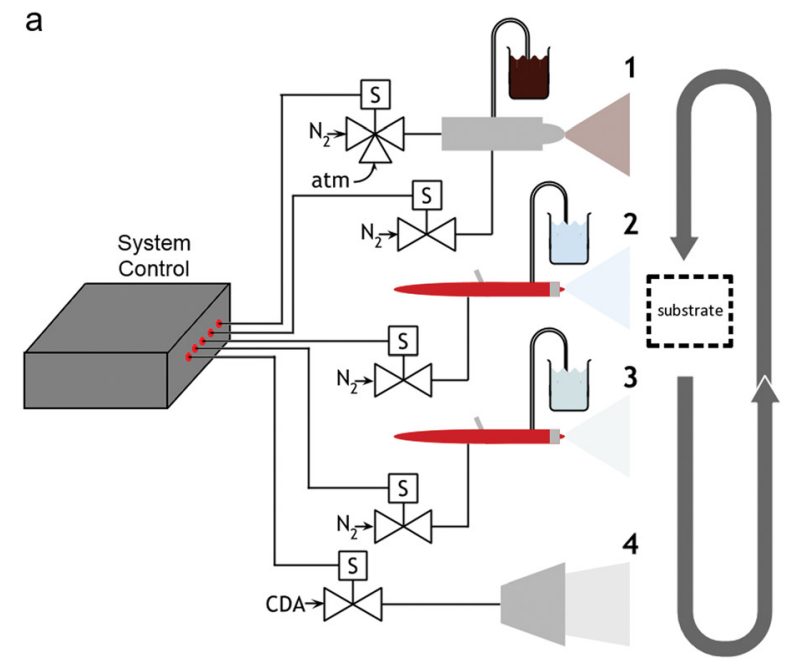

b

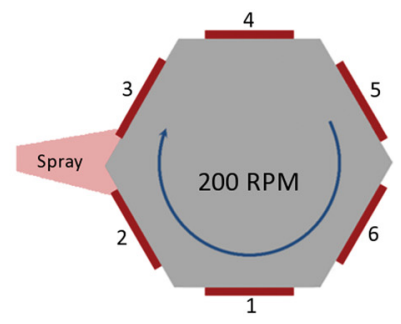

C

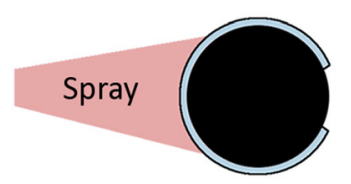

d

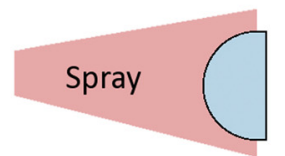

FIG. 1. (a) Full setup of layer-by-layer spray deposition. Stage 1 involves the fine mist spraying of CQDs. Stages 2 and 3 use commercial air brushes to spray MPA diluted in methanol and pure methanol, respectively. In stage 4, an air blade applies a curtain of high pressure compressed dry air to aid in solvent drying. In all stages, two-way valves control carrier gas pressure to the nozzle, while in CQD deposition stage, a three-way valve controls the pilot gas to actuate spraying. The looping of the sample through the 4 stages has been implemented as either a loop in space or in time (i.e., the sample moves or remains stationary, respectively). (b)-(d)-Top-view diagrams of substrates fixed on a rotating drum, flexible ITO-covered PET substrate (blue crescent) wrapped around a dowel (black circle), and spherical lens substrate (blue semicircle).

the air blade were pointed to the same physical location. The top contacts were deposited using an Angstrom Engineering $\AA$ mod deposition system in an Innovative Technology glovebox and consisted of $40 \mathrm{~nm}$ thermally evaporated $\mathrm{MoO}_{3}$ deposited at a rate of $1.0 \AA / \mathrm{s}$, followed by e-beam deposition of $50 \mathrm{~nm}$ of Au deposited at $1.5 \AA / \mathrm{s}$, and finally $120 \mathrm{~nm}$ of thermally evaporated $\mathrm{Ag}$ deposited at $2.0 \AA / \mathrm{s}$.

In order to simulate $\mathrm{R} 2 \mathrm{R}$ processing, we fabricated six samples simultaneously by affixing a substrate to each side of a hexagonal drum. The drum was then rotated at approximately 200 revolutions per minute during spray processing (Figure 1(b)). All nozzles remained focused at the same point in space, therefore some small additional delay equal the inverse of the rotational velocity were introduced into the procedure (approximately $0.3 \mathrm{~s}$ ) between spraying steps. Each substrate was FTO-covered glass with $50 \mathrm{~nm}$ of sputtered $\mathrm{TiO}_{2}$, and treated with a $\mathrm{TiCl}_{4}$ solution as in previous studies. ${ }^{12}$ Each side of the hexagonal drum was $5 \mathrm{~cm}$ in length; this test was therefore analogous to a roll of substrate passing through the active-layer deposition stage of fabrication at $1 \mathrm{~m}$ per second. This test was performed to verify the ability of the spray-coating method to be integrated into a $\mathrm{R} 2 \mathrm{R}$ processing protocol without compromising device performance.

Current-voltage characteristics were measured using a Keithley 2400 source meter. The samples were illuminated through a circular $0.049 \mathrm{~cm}^{2}$ aperture which was slightly smaller than the top electrode to avoid overestimating the photocurrent: the entire photon fluence passing through the aperture was counted as incident on the device for all analyses of short-circuit current density $\left(\mathrm{J}_{\mathrm{SC}}\right){ }^{16}$ The spectral mismatch of the system was characterized using a calibrated reference solar cell (Newport). The total AM 1.5 spectral mismatch was measured to be 5\%; therefore the multiplicative factor, $\mathrm{M}=0.95$, was applied to the current density values of the J-V curve to estimate true AM 1.5 performance. ${ }^{17}$ The resultant current-voltage curves under AM1.5 illumination of the six substrates fabricated on a rotating drum are shown in Figure 2(a), with average figures of merit of all six devices provided in Table I. The six samples are remarkably consistent (Figure 2, left), providing a mean power conversion efficiency $(\eta)$ of $6.7 \%$ with a relatively small standard deviation of $0.4 \%$ (Table I). Key figures of merit are also shown over time highlighting the stability and lack of sample-to-sample variability of the process (Figure 2, right). Since the total continuously-sprayed area exceeded $60 \mathrm{~cm}^{2}$, and $\eta$ was undiminished compared to the relevant standalone controls, ${ }^{12}$ it is clear that the sprayLD process can provide uniformity of yield and consistency of performance over areas of interest for scale-up manufacturing.
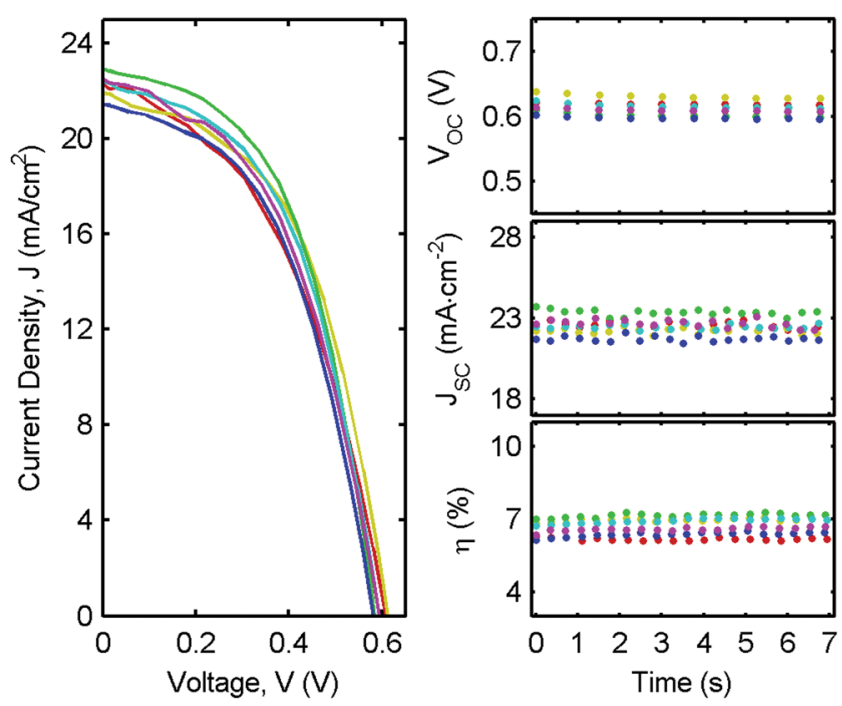

FIG. 2. (left) J-V curves of devices that were fabricated while mounted to a rotating drum (each sample is given a different color). (right) Figures of merit over time highlighting the small variation over the six samples. Static measurements illustrate the absence of transient or hysteretic behaviour. Data points are color coded to the J-V curves at left. 
TABLE I. Photovoltaic figures of merit for the three device configurations described above. The second column shows typical figures of merit for a standard device from along with the best reported in parentheses. ${ }^{12}$ The third column includes the standard deviation for the six devices that were fabricated simultaneously on the rotating drum. The other two columns represent champion performance.

\begin{tabular}{lcccc}
\hline \hline Figure of merit & SprayLD on glass substrate ${ }^{12}$ & Simultaneous spinning deposition & Flexible substrate & Spherical substrate \\
\hline $\mathrm{V}_{\mathrm{OC}}(\mathrm{V})$ & $0.58(0.60)$ & $0.61 \pm 0.01$ & 0.59 & 0.57 \\
$\mathrm{~J}_{\mathrm{SC}}\left(\mathrm{mA} \cdot \mathrm{cm}^{-2}\right)$ & $21.5(23.9)$ & $22.4 \pm 0.5$ & 22.9 & 54 \\
$\mathrm{FF}(\%)$ & $52(58)$ & $49 \pm 2$ & 7.2 & 4.7 \\
$\eta(\%)$ & $6.5(8.1)$ & $6.7 \pm 0.4$ & 6.8 & 5.0 \\
$\mathrm{R}_{\mathrm{S}}\left(\Omega \cdot \mathrm{cm}^{2}\right)$ & $7.0(4.7)$ & $8.1 \pm 1.1$ & 9.9 \\
\hline
\end{tabular}
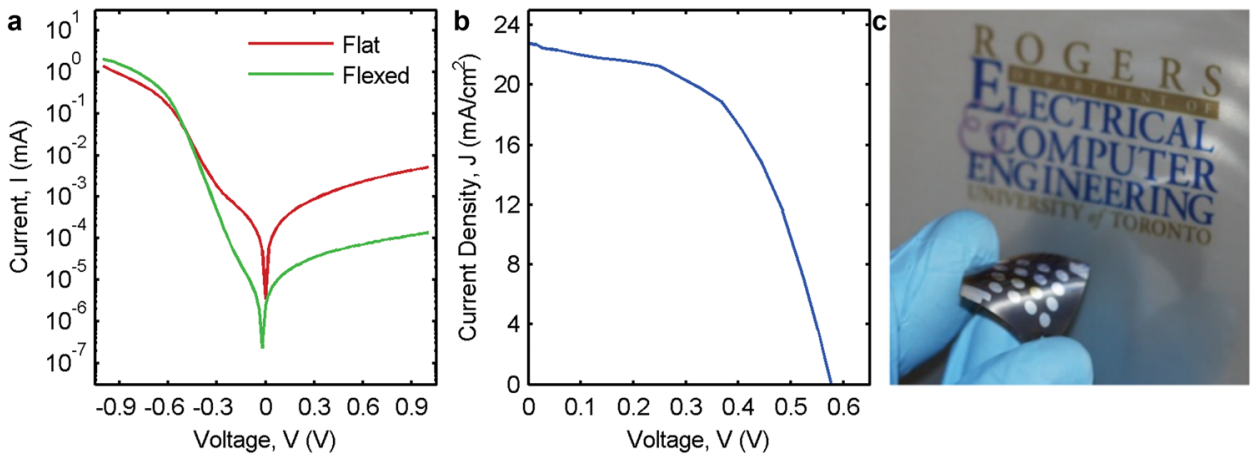

FIG. 3. (a) Dark J-V curves of sprayLD devices built on unflexed (red) and flexed (green) ITO-coated PED sheets. (b) Illuminated J-V curve of hero flexible device (green curve from a). (c) A photograph of a finished device that was sprayed on a flexible PET substrate while being wrapped around a $2 \mathrm{~cm}$ diameter dowel. The device was unwrapped and deposited with sixteen $6.7 \mathrm{~mm}^{2}$ devices (apertured down to $4.9 \mathrm{~mm}^{2}$ ) on the same substrate.
We sought also to showcase the spray-coating method on a flexible substrate. Flexible substrates lower the overall cost of a photovoltaic system through reducing the cost of the solar cell itself, the manufacturing technology required to build the cell, but—perhaps most profoundly—by reducing balance of systems costs by removing many of the structural engineering requirements imposed by heavy and rigid modules. Taken together, these cost savings lower the efficiency threshold for economic viability. ${ }^{18,19}$

We first built devices using indium tin oxide (ITO) coated on a flexible polyethylene terephthalate (PET) sheet. We mounted the sheet into our sputtering chamber and deposited $\mathrm{TiO}_{2}$ as in the case of FTO-coated glass substrates mentioned above. No $\mathrm{TiCl}_{4}$ treatment was done on these substrates as the PET would not support the high temperature anneal. We then used our sprayLD method to deposit the active layer onto the sheet. After spraying the substrate with our active layer, we unwrapped it from the dowel, cut it to size, and evaporated our standard contacts to make the finished flexible device shown in Figure 3(c). The device unfortunately generated an open-circuit voltage $\left(\mathrm{V}_{\mathrm{OC}}\right)$ of only $0.56 \mathrm{~V}$, a nearly $10 \%$ compromise relative to the typical device on a rigid substrate (Figure 1(a), inset).

We hypothesized that any flexing the device experienced between fabrication and testing would strain the semiconductor layers, providing recombination pathways and thus reducing $\mathrm{V}_{\mathrm{OC}}$. To test this, we measured the dark $\mathrm{J}-\mathrm{V}$ characteristics of the sample and found poor rectification (Figure 3(a), red curve). We further hypothesized that if we deposited all layers while the PET sheet was flexed, then when unflexed, the planar films would be compressed and therefore strain free. With this in mind, we wrapped the same ITO-coated PET sheet around a $2 \mathrm{~cm}$ diameter dowel and mounted the dowel into our sputtering chamber as before. After sputtering $\mathrm{TiO}_{2}$ and with the sheet still wrapped around the dowel, we used the optimized sprayLD method to coat a CQD layer onto it, as seen in Figure 1(c). The resultant dark I-V curve showed nearly a two order of magnitude

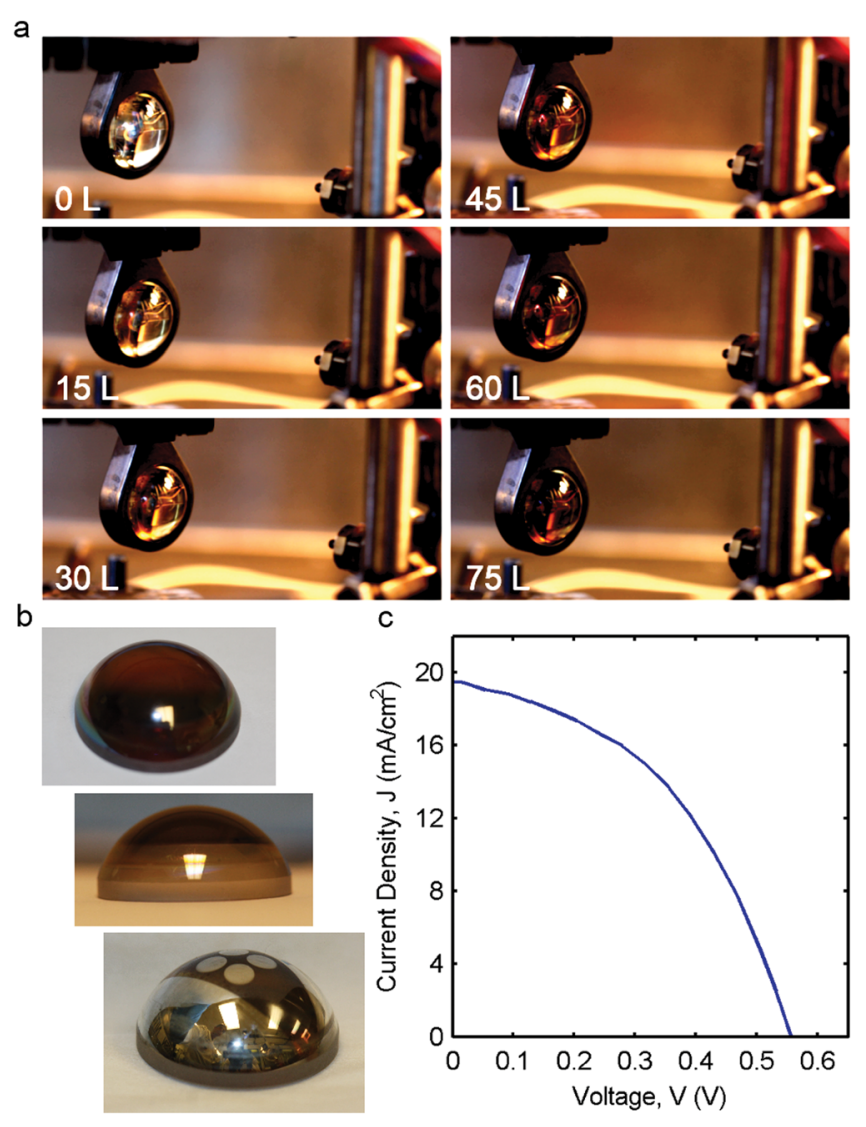

FIG. 4. (a) A time-lapse series of photos of a lens-shaped substrate as it is sprayed with the number of sprayed layers. (b) Top and side views of a spray-coated spherical lens illustrating coverage along multiple axes of curvature (top and middle) and a contacted spray-coated spherical lens solar cell device (bottom). (c) J-V curve of hero spherical device. 
improvement in reverse current rejection (Figure 3(a), green curve). The $\mathrm{V}_{\mathrm{OC}}$ was accordingly in far better agreement with the never-strained planar glass substrates at $0.59 \mathrm{~V}$ (Table I). Overall, we measured a $\eta$ of $7.2 \%$ (Figure 3(b)), in good agreement with our typical performance on a rigid glass substrate (Table I). ${ }^{12}$ Performance, therefore, does not suffer when applying our spray-coating method onto substrates that are commonly used for large area manufacturing, particularly when they are not flat during the deposition process.

While methods such as slot-dye or gravure are compatible with deposition onto flat substrates or around a single radius of curvature-a flexible substrate rolling around a cylindrical drum-they are less well-positioned to conform to a pre-formed curved part such as an airplane wing or an automobile fender. Spray-coating, attractively, allows direct deposition onto substrates of multiple-dimensionally curved shapes. In order to test our process's compatibility with two-dimensional curvature, we sprayed films onto spherical lenses (Thorlabs, LA1252, Figure 1(d)). $250 \mathrm{~nm}$ of ITO was deposited on the substrates via heated sputtering $\left(350^{\circ} \mathrm{C}\right)$, after which the samples were sputtered with $\mathrm{TiO}_{2}$ and treated with $\mathrm{TiCl}_{4}$ as described in our previous work. ${ }^{12}$ Figure 4(a) shows a time-lapse of the lens being covered by spraying layers, with images of the finished film and device shown in Figure 4(b) (additional time-lapse photos and videos are available via our prior publication ${ }^{12}$ ). The completed device achieved a $\eta$ of $5.0 \%$ (Figure 4(c), Table I), illustrating that our deposition method is highly versatile and can produce good-quality CQD films onto a variety of shapes.

We have shown that for CQD solar cells, best-in-class performance and manufacturability may be combined. By implementing device fabrication in a roll-to-roll environment, on flexible substrates and on curved surfaces, we have shown that colloidal quantum dot inks are compatible with scale-up manufacture.
The authors would like to thank Ikeuchi USA for useful discussions on the appropriate nozzles to use for our materials and solvents. This research was supported in part by IBM Canada Research and Development Center. This publication is based in part on work supported by Award KUS-11-009-21, made by King Abdullah University of Science and Technology (KAUST).

${ }^{1}$ E. H. Sargent, Adv. Mater. 17, 515 (2005).

${ }^{2}$ I. J. Kramer and E. H. Sargent, Chem. Rev. 114, 863 (2014).

${ }^{3}$ G. I. Koleilat, I. J. Kramer, C. T. O. Wong, S. M. Thon, A. J. Labelle, S. Hoogland, and E. H. Sargent, Sci. Rep. 3, article number 2166 (2013).

${ }^{4}$ C.-H. M. Chuang, P. R. Brown, V. Bulović, and M. G. Bawendi, Nat. Mater. 13, 796 (2014).

${ }^{5}$ Y. Gao, E. Talgorn, M. Aerts, M. T. Trinh, J. M. Schins, A. J. Houtepen, and L. D. A. Siebbeles, Nano Lett. 11, 5471 (2011).

${ }^{6}$ O. E. Semonin, J. M. Luther, S. Choi, H.-Y. Chen, J. Gao, A. J. Nozik, and M. C. Beard, Science 334, 1530 (2011).

${ }^{7}$ P. Kumar, S. Kannappan, S. Ochiai, and P.-K. Shin, J. Korean Phys. Soc. 62, 1169 (2013).

${ }^{8}$ V. A. Akhavan, B. W. Goodfellow, M. G. Panthani, D. K. Reid, D. J. Hellebusch, T. Adachi, and B. A. Korgel, Energy Environ. Sci. 3, 1600 (2010).

${ }^{9}$ T. Suntola, Mater. Sci. Rep. 4, 261 (1989).

${ }^{10}$ S. M. George, Chem. Rev. 110, 111 (2010).

${ }^{11}$ N. P. Dasgupta, H. J. Jung, O. Trejo, M. T. McDowell, A. Hryciw, M. Brongersma, R. Sinclair, and F. B. Prinz, Nano Lett. 11, 934 (2011).

${ }^{12}$ I. Kramer, J. Minor, G. Moreno-Bautista, L. Rollny, P. Kanjanaboos, D. Kopilovic, S. M. Thon, G. H. Carey, K. W. Chou, D. Zhitomirsky, A. Amassian, and E. H. Sargent, "Efficient Spray-Coated Colloidal Quantum Dot Solar Cells," Adv. Mater. (in press).

${ }^{13}$ A. G. Pattantyus-Abraham, I. J. Kramer, A. R. Barkhouse, X. Wang, G. Konstantatos, R. Debnath, L. Levina, I. Raabe, M. K. Nazeeruddin, M. Grätzel, and E. H. Sargent, ACS Nano 4, 3374 (2010).

${ }^{14}$ M. a. Hines and G. d. Scholes, Adv. Mater. 15, 1844 (2003).

${ }^{15}$ A. H. Ip, S. M. Thon, S. Hoogland, O. Voznyy, D. Zhitomirsky, R. Debnath, L. Levina, L. R. Rollny, G. H. Carey, A. Fischer, K. W. Kemp, I. J. Kramer, Z. Ning, A. J. Labelle, K. W. Chou, A. Amassian, and E. H. Sargent, Nat. Nanotechnol. 7, 577 (2012).

${ }^{16}$ H. J. Snaith, Nat. Photonics 6, 337 (2012).

${ }^{17}$ J. M. Kroon, M. M. Wienk, W. J. H. Verhees, and J. C. Hummelen, Thin Solid Films 403-404, 223 (2002).

${ }^{18}$ M. Graetzel, R. A. J. Janssen, D. B. Mitzi, and E. H. Sargent, Nature 488, 304 (2012).

${ }^{19}$ I. J. Kramer and E. H. Sargent, ACS Nano 5, 8506 (2011). 